\title{
Method of Mapping and Classification of Eroided Land in Azerbaijan
}

\author{
Rans Aliyev ZH* \\ Institute of Soil Science and Agro chemistry of NAS of Azerbaijan, Azerbaijan
}

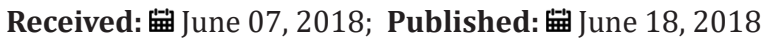

*Corresponding author: Rans Aliyev ZH, Institute of Soil Science and Agro chemistry of NAS of Azerbaijan, Azerbaijan

\section{Introduction}

In the conditions of Azerbaijan, erosion, causing erosion, erosion and deflation of soils, has developed a great deal. It is most distinctly expressed on soils cultivated in conditions of rain fed agriculture that are not secured and semi-provided with rainfalls. In order to solve the problems of rational use of lands subject to erosion or potentially erosion-hazardous, it is necessary to deeply understand each land mass of the farm, its features that can influence the choice of crops for those or other general measures, or private methods of agricultural technology. Obtaining such data is possible only as a result of large-scale surveys of the territory. Depending on the degree of loss of the upper horizons of the soil, usually very weak, medium, strong and very strongly eroded soil differences are isolated. The more the soils are eroded, the more they differ from their non-washed analogues in chemical, granulometric composition and physico-chemical properties, water, air and heat regimes, biogenicity and other indicators, the aggregate of which affects fertility and their erosion resistance. The nature of the changes in the granulometric composition of soils during the development of erosion is mainly determined by the degree of its homogeneity in the depth of the profile. If the soils are fertile, then undiluted and washed-out varieties are few by this feature. In the washed-out soil, the silt fraction is markedly reduced. In eroded soils, the mineralogical composition of the arable changes in connection with its change in the depth of the soil profile. Very large changes in the granulometric and mineralogical composition are observed on strongly washed soils.

With increasing soil erosion, the content of humus decreases. If the humus content of the $0-50 \mathrm{~cm}$ layer is $168 \mathrm{t} /$ ha in undistorted mountain brown ostepen soils, then in the very weakly washed $-156 \mathrm{t} / \mathrm{ha}$, in the slightly washed-135t/ha, in the medium-washed $-108 \mathrm{t} / \mathrm{ha}$, in the strongly washed-65t/ha, and in very strongly washed-32t/ha. In eroded soils, not only does the content of humus decrease, but its qualitative composition also changes, the ratio of carbon to nitrogen narrows, thereby increasing the amount and reducing the ratio of humic acids to fulvic acids. Accordingly, the content of mobile forms of humic acids decreases. In A. Tanasienko's opinion, these changes are stronger the more eroded soil. Reduction of humic acids leads to a decrease in fertility to a deterioration of the erosion resistance of the soil. The stronger the soils are eroded, the less they contain humus. This decrease, in general, is proportional to the decrease in nitrogen in the soil. In addition, in eroded soils, the percentage of assimilable forms of nitrogen, in particular nitrate in ammonium forms, is lower than in non-eroded varieties. A decrease in the content of hydrolyzable nitrogen and nitrates in 1.5-2.0 times is found in the mediumwashed soils. The shortage of available forms of nitrogen is one of the important reasons for the decline in the fertility of washed-out soils. With a clear regularity, a decrease in P205 is also observed, in medium-washed soils it is $30 \%$ and in highly washed soils it is more than $50 \%$. Reduction of organic phosphate content and growth of sparingly soluble forms of phosphorus lead to deterioration of phosphorus nutrition of plants. In eroded soils, the content of potassium often decreases. Thus, according to its agrochemical characteristics, the washed-out soils are significantly different from the non-washed soils. Hence the need for a different application of soil fertilizers with different degrees of erosion. Eroded soils differ significantly from non-eroded soils by their physical properties. In eroded soils, the content of waterproof structural aggregates decreases. So, if the content of water-resistant aggregates is $52 \%$ in the upper horizon, then the content of water-resistant aggregates is $48 \%$, in the slightly washed- $42 \%$, in the medium-washed $30 \%$, strongly washed $18 \%$, and in very strongly washed $8 \%$. In this case, the number of aggregates less than $0.25 \mathrm{~mm}$ increases (Table 1 ). 
Table 1: Diagnostic indicators of different degrees of erosion of mountain-brown steppe soils.

\begin{tabular}{|c|c|c|c|c|c|c|}
\hline \multirow{2}{*}{$\begin{array}{l}\text { Degree of erosion } \\
\text { and its designation }\end{array}$} & \multirow{2}{*}{$\begin{array}{l}\text { The thickness of } \\
\text { the horizons A + B }\end{array}$} & \multicolumn{3}{|c|}{ Gross reserves, $t$ / ha } & \multirow{2}{*}{$\begin{array}{l}\text { Waterproof aggregates more than } \\
\qquad 1 \mathrm{~mm} \%\end{array}$} & \multirow{2}{*}{$\begin{array}{l}\text { Productivity } \\
\text { ц/га }\end{array}$} \\
\hline & & humus & nitrogen & phosphorus & & \\
\hline phosphorus & 75 & 168 & 10,5 & 6,4 & 52 & 28,5 \\
\hline Very weakly eroded & 70 & 156 & 8,8 & 5,8 & 48 & 26,2 \\
\hline Low-eroded & 60 & 135 & 7,6 & 5,0 & 42 & 22,3 \\
\hline Middle Aged & 45 & 108 & 5,6 & 3,2 & 30 & 15,8 \\
\hline Heavy-Carried & 30 & 65 & 3,8 & 2,3 & 18 & 9,8 \\
\hline Very strongly eroded & $<15$ & 32 & 1,9 & 1,2 & 8 & 6,4 \\
\hline
\end{tabular}

Non-eroded soils differ from eroded by a marked differentiation of the soil profile and greater thickness. Good arable and subsoil layers. In the latter there appears a gray-brown tinge-the influence of the illuvial horizon B. In the subsoil layer, compaction is noticeably found and in some places carbonates are separated. The structure is silty-lumpy, while in virgin soils it is well-defined cloddy. The degree of erosion for each subtype of soils is determined depending on which part of the soil profile is washed away or deformed, from which horizons the arable layer is formed, what is the average yield in percent compared to the yield on non-eroded soils, and what is the slope of the slopes in degrees. The degree of erosion of soils also depends on the shape of the slope, its length and exposure, the correctness of economic use, erosion resistance, which includes a variety of mechanical, chemical and physical properties. Therefore, on the slopes of the same steepness of the soil there can be one subtype, but of different erosion. The average yield is an important indicator when determining the degree of erosion of soils. In the field, the fertility of soils was determined visually, according to the morphological features of the soil profile and the state of the plants in this area. From the data of Table 1, it is seen that as the degree of erosion increases, a decrease in the thickness of the horizons $A+B$ of the humus reserve is observed within certain limits [1]. It should be noted that the reserve of humus (in tonnes) is calculated taking into account nitrogen and phosphorus. In addition, the data on the yield, the reduction in the classification of eroded soils, is somewhat understated. Subsequent our many years of research indicators that the yield of winter wheat on very slightly eroded mountain brown soils is reduced to an average of $10 \%$ on mediumeroded soils, to $25 \%$, and on highly eroded soils, to $75 \%$ compared to yields on non-eroded soils.

Taking into account local peculiarities of soils, we adopted the following grouping according to the degree of soil erosion. The erosion of lands, which is established depending on the steepness and exposure of slopes, the depth of local erosion bases, the degree of erosion, the nature of the underlying rocks, and belonging to one or another agricultural land. The slope gradients for arable land were taken as follows: $0-1 ; 1-3 ; 3-5 ; 5-8 ; 8-12$ and more 12 . For other lands $0-1 ; 1-3 ; 3-5 ; 5-8 ; 8-12 ; 12-20 ; 20-30 ; 30-45$ and more. The following gradations were taken from the slope exposition: northern, north-eastern, northeast, north-west, east, west, southwest, south-east and south Gradation of the depth of local erosion bases was as follows: $0-20 ; 20-50 ; 50-100 ; 100-150 ; 150-200 ; 200-$ $300 ; 300-400 ; 500-600 ; 600-800 ; 800-1000 \mathrm{~m}$ and more. By the degree of erosion, different categories of eroded lands are contained as soils of one degree of erosion, and their various complexes. The nature of the underlying rocks and their density were also taken into account. For each of the selected groups and categories of eroded land, recommendations were given on their use and on the application of anti-erosion measures. The main features of eroded lands are soil maps, which reflect all the contours of washed-up soils and agricultural lands. The auxiliary special maps of steepness, exposure of slopes and the depth of local erosion bases were also used. In recent years [2], there has been a significant increase in the area of eroded soils, which is due to the thoroughness of the research on the allocation of eroded lands that were not previously taken into account.

First of all, the question arises of diagnostic indicators for assessing the degree of erosion of soils. Sometimes indicators that determine the danger of erosion are used. For example, in a number of cases, the assessment of the erosion of arable soils is established on the basis of data on the distribution of arable land along slopes. Of course, the steeper the slopes, the other conditions being equal, the degree of soiliness of soils increase [3]. However, these equal conditions are not always available; therefore soils on steeper slopes can be less eroded than on sloping ones (Table 2). As can be seen from the data in Table 2, in the north-eastern part of the Greater Caucasus, arable land is more favourable under relief conditions than in the south-eastern or southern parts of the Greater Caucasus. Therefore, the soil cover here is relatively less eroded. This is largely due to the relatively greater erosion resistance of soils, a favorable regime of precipitation and the soilprotective role of vegetation. Soil-erosion studies in the Republic of Azerbaijan show that the factor-exposure of slopes often affects the distribution of eroded soils more often than the steepness of the slopes. So in the forest zone, when examining the mountain-brown ostepennyh soils on one of the sections with slopes of 15-200 on the southern slope, highly eroded soils were found, and on the slopes of the northern exposure with a slope of 15-200-slightly eroded. The great influence of the exposure of slopes on the distribution of soils was established. Thus, on the slopes of the northern exposition with gradients of 8-120 on mountain-brown graded soils, the washout is $19.2 \mathrm{~m} / \mathrm{ha}$, and under similar conditions of southern exposure 
the washout of soils reaches $45.8 \mathrm{~m} / \mathrm{ha}$. If the medium and highly eroded soils occupy $41.2 \%$ of the area on the slopes of the southern exposure, only $9.8 \%$ on the slopes of the northern exposure under similar conditions [4].

Table 2: Degree of soil erosion.

\begin{tabular}{|c|c|c|c|}
\hline $\begin{array}{c}\text { Grades of } \\
\text { growth }\end{array}$ & $\begin{array}{c}\text { Flushing } \\
\text { of genetic } \\
\text { horizons, } \%\end{array}$ & $\begin{array}{c}\text { Reduction of } \\
\text { the reserve of } \\
\text { humus, } \%\end{array}$ & State of crops \\
\hline $\begin{array}{c}\text { Very weakly } \\
\text { eroded }\end{array}$ & A to 20 & $<10$ & Good \\
\hline Low-eroded & A $20-50$ & Oct-25 & $\begin{array}{c}\text { Slightly below } \\
\text { average }\end{array}$ \\
\hline Medium-eroded & And completely & $25-50$ & Average \\
\hline Heavy-Carried & In about 50 & $50-75$ & Cut out \\
\hline $\begin{array}{c}\text { Very strongly } \\
\text { eroded }\end{array}$ & In full & $>75$ & Very bad \\
\hline
\end{tabular}

The areas of all types of landings and groups of eroded lands were calculated taking into account genetic types of soils. As a result, it became possible to make explications of the eroded lands of the republic. The explication contains data on the quantity of each type of eroded soils of different degree of erosion on certain surface slopes, in the composition of various agricultural lands. Further generalization of the materials of land erosion consists in reducing them to republican maps, where dependence on the soil cover is shown for the purpose of zoning erosion measures. For the allocation of eroded areas, the following gradation is the basis for the allocation of land erosion. Based on the mapping data of eroded soils, as well as cameral works, a map of the erosion of the soils of the Azerbaijan Republic was compiled with the following application:

\section{Areas of no erosion}

a) Not subject to soil erosion under forests;

b) Not subject to soil erosion, occupation by natural haymaking and marsh vegetation;

c) Soils, confined to such lands as fields, gardens.

\section{Areas subject to erosion}

Depending on the number of soils with different degrees of destruction of genetic horizons, the earth's are divided into five groups:

a) Very weakly eroded land, where low-erosion differences are no more than $10 \%$ and medium- and heavily washed soils are absent.

b) Low-eroded land, where the total area of eroded differences is up to $25 \%$. Areas of weakly washed soils- $20 \%$, medium-washed-no more than $5 \%$, and strongly washed soils are absent.

c) Medium-eroded soils: Total eroded soils up to $50 \%$. The area of contours with medium-eroded soils reaches $30 \%$, slightly eroded to $15 \%$ and heavily eroded soils up to $5 \%$, and highly eroded soils are absent.

d) Strongly eroded soils.

e) The erosion of soils is about $75 \%$ of the total area. $40 \%$ of them are highly eroded, medium-eroded - up to $25 \%$ and highly-eroded ones - $10 \%$.

f) Very heavily eroded soils. Eroded areas account for more than $75 \%$. Of these, very strongly eroded - more than $50 \%$, medium, strongly eroded - more than $25 \%$.

Taking into account the experience of our work, we fully share the views of ASKozmenko, GA Presnyakov, SSSobolev, KA Alekperov, MNZaslavsky that the color of the topsoil can be taken as the indicator erosion.

In the undistorted-the color is dark brown, the humus content is $5.0 \%$, nitrogen is $0.30 \%$, phosphorus is $0.22 \%$, the absorption capacity is 35 meq per $100 \mathrm{~g}$ of soil, the water resistance of structural aggregates is more than $1 \mathrm{~mm} 52 \%$.

a) Very weakly washed: Horizon A is washed no more than $20 \%$, the color of the soil differs little from those that are not washed. The humus content in the upper horizon is $4.6 \%$, nitrogen $0.28 \%$, phosphorus $0.19 \%$, absorption capacity 32.5 meq, the number of water-tight aggregates more than $1 \mathrm{~mm}$ $48 \%$. Productivity is below $10 \%$ than in non-washed products.

b) Slightly washed: Horizon A 20 to $50 \%$ washed away, the color is brown, the humus content is $4.0 \%$, nitrogen is $0.24 \%$, phosphorus is $0.16 \%$, the absorption capacity is 28.8 meq, and the number of waterproof aggregates is $48 \%$. Yields are lower (from 10 to $25 \%$ ) than those that are not smashed.

c) Medium-blurred: Horizon A is completely washed away, the color of the soil is light brown, the humus content is $2.8 \%$, nitrogen is $0.18 \%$, phosphorus is $0.10 \%$, the absorption capacity is 23.8 meqv, the water-strength aggregates are $30 \%$, yields are below 25 to $50 \%$ than that of non-washed ones.

d) Strongly washed: The horizon B1 is washed, the colour of the soil is yellowish with a brownish hue. The humus content is $-1.2 \%$, nitrogen is $0.8 \%$, phosphorus is $0.05 \%$, the absorption capacity is 14.5 meq, the water-strength aggregates are $18 \%$, the productivity is from 50 to $75 \%$ (Table 3 ).

Table 3: Classification of pasture erosion on mountain slopes.

\begin{tabular}{|c|c|c|}
\hline Stage & Power & Indicators \\
\hline \multirow{4}{*}{$\begin{array}{c}\text { Embossment } \\
\text { (tropechchatost) }\end{array}$} & Very weak & $\begin{array}{c}\text { Total track area: }<10 \% \\
\text { of the total area }\end{array}$ \\
\cline { 2 - 3 } & Weak & $10-25 \%$ \\
\cline { 2 - 3 } & Average & $25-50 \%$ \\
\cline { 2 - 3 } & Strong & $50-75 \%$ \\
\hline
\end{tabular}


e) Very strongly washed: washed completely soil layer, on the surface exposed loose and hard rocks. The general classification of washed-away soils is as follows: the choice of diagnostic indicators to determine the degree of erosion of soils, the appropriate amount of allocated levels of soil erosion, standards to establish their degree of erosion.

For mountain-brown ostepenennyh soils, the degree of erosion is proposed to be determined by reducing the genetic horizons and reducing the humus content in horizons $\mathrm{A}+\mathrm{B}$. To very poorly eroded, it is recommended to refer to soils, in which, in comparison with the undisturbed, a decrease in the horizon A to $20 \%$ and a reserve of humus to $10 \%$, to slightly eroded, respectively, 10 $25 \%$, to medium eroded-25-50\%, to strongly erode $-50-75 \%$. These gradations are proposed taking into account the variation of humus content in non-washed soils and errors in laboratory determinations. Determination of the degree of soil erosion based on the quantitative indicator of the humus content in the surface layer of the soil is an accurate and objective method that can be fully used for soil-erosion mapping of mountain-brown steppe soils and genus soils close to them in genesis Natural hayfields and pastures, constantly covered with vegetation, are considered the most effective anti-erosion form of land use. However, due to the deprivation of the protective cover on the slopes, the surface runoff of soils increases, which contributes to the intensification of the erosion process [5].

In its geographical distribution erosion processes on pastures are manifested in a certain zonal subordination, which is confined to certain bioclimatic zones and is, as it were, a product of the development of this bioclimatic environment. Depending on the degree of development of the erosion process, the nature of the vegetation cover and the soil-forming rocks, each identified type of erosion is subdivided into subtypes and varieties [6]. The grouping of eroded soils of the republic covers the main natural-landscape zones, taking into account the landscape-climatic conditions of each zone. The climate of the high mountains is characterized by a severe long winter with long snow cover and frost. Summer is short and cool. The average annual temperature does not exceed 3.2-4.10, and the cold month (January) varies from -4.6 to 7.90 , the temperature of the warm month (July) is low, varies from 12.9 to 13.70 , the sum of the temperatures is higher 100 is very low and does not exceed 800-600 on the average. The duration of the frost-free period is 1-2 months; the growing season lasts about 90 120 days. The average annual precipitation is $610-1210 \mathrm{~mm}$, the wetting factor is 1.52-1.22, and the total solar radiation (annual) varies within the limits of $144-156 \mathrm{kcal} / \mathrm{cm} 2$. According to the reduction of climatic parameters, the entire high-mountain area refers to the wet $(\mathrm{MD}<0.45)$ and cold $(\Sigma \mathrm{T}>800)$ climatic type. Vegetation by floral composition is extremely heterogeneous and varies with the altitude of the terrain. In the most elevated part of the zone, the vegetation is represented not by closed cover-groups of rocky assemblages (lichens, algae, etc.). For alpine meadows, dense-grassy meadows with grassy components are characteristic. Subalpine meadows are represented by cenoses of grasses, mixed herbs, rhododendron thickets, and in relatively dry parts by meadow-steppe communities.

The main types of soils are represented by mountain meadow, mountain-forest-meadow and mountain-meadow-steppe soils. Agricultural development is weak; the territory of the zone is mainly occupied by rich summer pastures and hayfields and is the basis for the development of transhumant livestock (sheep breeding) and fodder production. In alpine and subalpine meadows, the main area of which is occupied by pastures, soil erosion is the factor with which the water balance of the area is closely related. Deprived of a protective cover, the soil of sloping lands does not have time to absorb thawed and rainwater. This leads to an increase in surface runoff, which contributes to increased pulsation of rivers. It is as a result of the violation of the hydrological regime of the territory, which is mainly due to the removal of forests and knocking out grassy vegetation, In the rivers of mountainous areas, quite often very strong falls are observed in the volume of river flow. A large loss of surface runoff water worsens the regime of the rivers, both snow and especially snow. This, in turn, reduces the irrigation capacity of rivers in the foothill plains, necessitating the use of large irrigation and drainage works. Erosion processes, which resulted from the deterioration of the vegetation cover of pasture lands, contribute to a sharp drop in pasture productivity. Therefore, soil erosion and deterioration in the quality of the grass stand are closely interrelated processes. Well-developed natural grass cover significantly increases the resistance not only to the quantitative indicators of pasture plants, but also leads to the reorganization of phytocenoses.

Out of the total area of 2402.3 thousand hectares of mountain pastures more than 1985.8 thousand hectares or $82.7 \%$ are subject to erosion processes. In pastures, depending on the subzone and the exposure of the slope, the washing of soils varies from 50 to $125 \mathrm{~m} 3$ / ha. From these studies it follows that the problem of studying pasture erosion in mountainous regions and the development of methods for preventing and combating it has been of great economic importance. When developing differential measures to improve and rational use of pastures, there is always a need to classify and group pasture lands according to their qualitative status. However, it should be noted that the issues of classification of pasture erosion have not been adequately developed at present. Moreover, even the phenomenon of erosion in pastures has not found a definite place in the general grouping of erosion processes, although the character of pasture erosion is very different from other types or categories of erosion [7]. According to the classification of eroded soils of mountain pastures, the works of VA Filkova (1958), D.Ya.Mikhailov (1959), S.U.Kerimkhanov (1972) are known. In these studies, the grouping of pasture soils in terms of the degree to which they are destroyed. 
In the forms of accelerated erosion caused by human economic activity, there is much in common. However, depending on the cause that caused the erosion, these forms also have their own peculiarities.

The nature of the erosion of soils of mountain pastures differs quite sharply from erosion on the cultivated slopes. On the pastures erosion processes begin to develop usually from the moment of damage to the sod with livestock. On mountain pastures, the process of soil destruction has no similarity to the formation of patches and ruts. The length of the pits does not always exceed their width, and the presence under the thin soil layer of a waterproof dense rock nullifies the growth of the pit into the depth. Further growth in the size of erosion pits, as a rule, occurs by breaking walls, slipping along the slope with the remaining places of the sod of woven roots and resembling the formation of a ravine in the second stage of its development. The erosion pits that arise not far from each other often have vertical walls and, expanding, join together, forming sections or bands of eroded soil. With further destruction of the soil, a more or less gradual alignment of the tuberculation micro relief occurs both by shedding and under the influence of the slope runoff. Such a specific character of erosion processes on mountain pastures requires, firstly, the allocation of pasture erosion into an independent subtype or category, and secondly, the development of appropriate classification of soils in terms of their erosion.

On the basis of long-term observations, taking into account the specific features of the development of destructive processes in soils due to the influence of immodest pasture of cattle, a draft classification of pasture erosion by the degree of erosion is proposed (Table 3). This takes into account the sequence of the deformation process of the tufted layer. The results of the studies indicate the possibility of using the cultivated vegetation of arable land and the grass stand of natural meadows in order to clarify the data of the soil-erosion survey. On the areas occupied by sowing field crops are the signs by which the degree can be determined. With the increase in the steepness of the slopes, the possibility of using cultivated crops as indicators of soil erosion decreases. The degree of washout of soils in natural soils of fodder lands can be estimated on the basis of the dependence of the existing between the height of the plant stand and the degree of soil erosion. A sufficiently strong erosion of soils in sloping meadows can be recognized by ecological regimes of habitats of vegetation.

\section{References}

1. Aliyev GA (1978) Soil the Greater Caucasus (within the Azerbaijan SSR). Part 1. IZD-vo Elm.

2. Aliyev BH (2000) Problems of Geology and Hydrogeology of Apsheron Baku.

3. BH Aliev, Aliev ZH (2003) Irrigated agriculture in the mountain and foothill regions of Azerbaijan. Monograph Publishing house Naji Zia EPG Ltd, Baku, pp. 330.

4. Aliev BH, Aliev ZH (1999) Techniques and technology few intensive irrigations in condition of the mountain region of Azerbaijan. Publishers Elm, Baku, pp. 220.

5. Romanenko VD, Oksijuk OP, Zhukinskij VN, A.stolberg (1990) Environmental assessment of the activity of hydrotechnical building on water objects, Naukova dumka, Kiev.

6. Lavrik VI (1984) Human Heredity and the environment Wednesday. Soviet Committee for the UNESCO programme,man and the Biosphere Programme. Nauka, Moscow.

7. (1989) General Oncology (Edn) Academy of medical sciences of ussr NP Napalkova S, medicine.
(C) (P) This work is licensed under Creative

To Submit Your Article Click Here: Commons Attribution 4.0 License Submit Article
DOI: $10.32474 /$ CIACR.2018.03.000156

Citation: Rans A ZH. Method of Mapping and Classification of Eroided Land in Azerbaijan. Curr Inves Agri Curr Res 3(2)- 2018. CIACR. MS.ID.000156. DOI: 10.32474/CIACR.2018.03.000156.

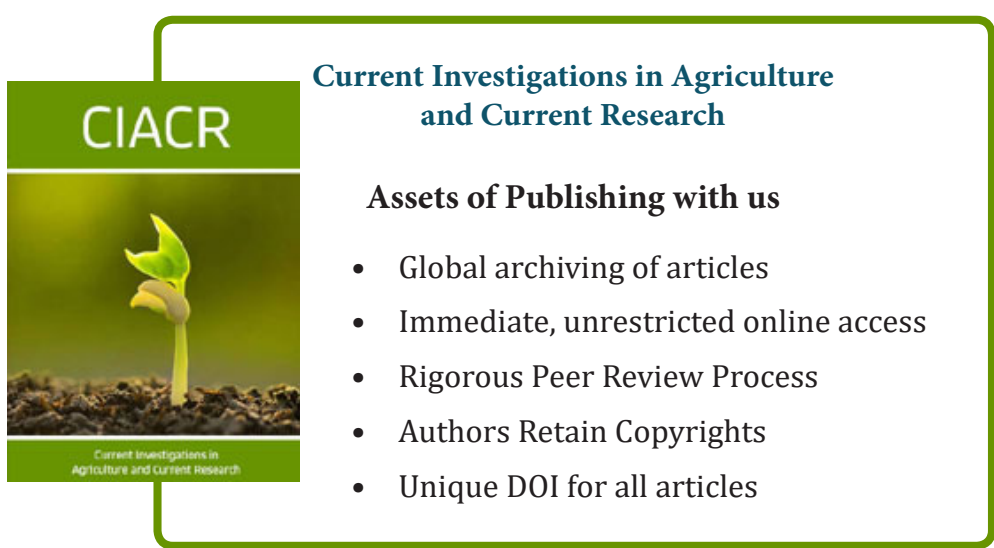

